\title{
Aproximación teórica al debate por el reconocimiento político, jurídico y social del sector $\mathrm{LGTBIQ}^{1}$
}

\author{
Carlos Andrés Duque Acosta
}

\begin{abstract}
The traditional discrimination against non-heterosexual orientations and expressions has been losing its legitimacy during the last decades. This fact does not imply, however, that there is unanimity about which theoretical and discursive basis is more pertinent for the demand of rights for gays, lesbians and transsexuals, amongst others. This article critically revises three political paradigms that are incumbent in this debate: the politics of liberalism, the politics of difference and the politics of cultural transformation. Thereafter, it discusses the theoretical proposal of Nancy Fraser to see the lack of recognition as a status subordination problem, which is complemented by Chantal Mouffe's proposal for the construction of radical democracy.
\end{abstract}

\footnotetext{
${ }^{1}$ La abreviatura o acrónimo LGTBIQ, además de explicitar algunas definiciones relacionadas con la diversidad de orientación sexual y de expresión de género, busca ser descriptiva e incluyente. Aunque reconozco la dificultad inherente a las clasificaciones dicotómicas y las taxonomías en este difuso tema, y sobre todo la discutible existencia de orientaciones e identidades sexuales y de género fijas, se intenta con ella dar algunas definiciones para ilustrar a las personas que no estén muy familiarizadas con el tema. Así, LGTBIQ se refiere a Lesbianas (mujeres homosexuales: es decir, orientadas erótico-afectivamente hacia personas de su mismo sexo); Gays (hombres homosexuales); Bisexuales (personas orientadas erótico-afectivamente hacia ambos sexos); Transgénero (personas que trascienden o rompen las definiciones convencionales de hombre y mujer, no sólo en su aspecto físico sino también en sus actitudes, maneras y gestos. El género hace referencia a la forma en que una persona se percibe a si misma en relación con las concepciones socioculturales de masculinidad y feminidad. Los transgénero pueden o no iniciar cambios en su cuerpo); Transexuales (personas que han decidido mediante un proceso quirúrgico cambiar sus órganos sexuales externos); Transvestis (parte del grupo transgénero, que se sienten y se visten de tiempo completo siguiendo los modelos establecidos para el género opuesto) y Transformistas (transvestis ocasionales, para presentaciones o espectáculos); Intersexuales (personas que biológicamente desarrollan las características físicas y genitales de ambos sexos, sobre las cuales recae doblemente discriminación por razones de orientación sexual y expresión de género y son mutiladas al nacer con base en arbitrarias decisiones discriminatorias); Queer (del inglés: raro, extraño. Personas que no se enmarcan en ningún tipo de categoría identitaria sexual o de género y están enmarcados en un movimiento contracultural que desafía la existencia de tales categorías para definir la diversidad sexual). Estos datos están basados en el texto producido por la fundación Colombia Diversa: Voces excluidas: legislación y derechos de lesbianas, gays bisexuales y transgeneristas en Colombia. Autores varios. Tercer Mundo Editores. Bogotá. 2006.
} 


\section{Breve aproximación a la discriminación y exclusión contra el sector LGTBIQ}

En este primer acápite presentaré tres aproximaciones teóricas al tema de la discriminación y exclusión contra el sector LGTBIQ. De manera concreta y puntual, expondré una caracterización del tipo específico de subordinación que sufren las personas pertenecientes a este sector poblacional. Es importante aclarar, desde el principio, que la mayoría de autores y autoras se han referido a este tema centrándose en el concepto de homofobia, ${ }^{2}$ que en general ha pretendido abarcar la discriminación y exclusión a personas no heterosexuales. Me centraré por su importancia y pertinencia para mis propósitos argumentativos en los trabajos de Nancy Fraser, Pierre Bourdieu y Judith Butler.

Para la filósofa norteamericana Nancy Fraser, el sector LGTBIQ sufre básicamente un problema de injusticia simbólica (desde luego desencadenador de violencia física), es decir, un problema de injusticia arraigado en los patrones sociales de representación, comunicación e interpretación de la realidad. En palabras de la autora:

Este tipo de injusticia incluye la dominación o imperialismo cultural (estar sometido a patrones de interpretación y comunicación asociados con otra cultura y extraños u hostiles a los propios); el no reconocimiento (invisibilización a través de las prácticas representacionales, interpretativas y comunicativas autorizadas de la propia cultura); y el irrespeto (ser agredido, calumniado o menospreciado habitualmente en las representaciones culturales públicas estereotipadas o en las interacciones cotidianas) (Fraser, 1997: 22).

Esta injusticia simbólica ejercida contra el sector LGTBIQ está fundamentada, en la cultura patriarcaloccidental, ${ }^{3}$ en el androcentrismo: patrón institucionalizado

\footnotetext{
${ }^{2}$ El concepto de homofobia es un término problemático, incluso mal utilizado, ya que el concepto de fobia desde el punto de vista clínico tiene otras connotaciones relacionadas con reacciones fisiológicas de carácter fóbico. Contra el no heterosexual existe en muchos casos algo semejante al odio que sentían los nazis contra los judíos (odio fundamentado en connotaciones socioculturales y no tanto psicológicas). Aunque es un término políticamente estratégico, igual deja por fuera el rechazo y discriminación contra los transgeneristas y los transexuales y contra los bisexuales e intersexuales. Aquí también se podría hablar además de lesbofobia, bifobia y transfobia, para ser más incluyentes y descriptivos.

${ }^{3}$ En palabras del profesor Carlos Arango: "Ser hombre o mujer solamente tiene sentido en una sociedad patriarcal. La estrategia patriarcal implica la adopción de tres operaciones sobre la experiencia humana a partir de la manipulación de los principios de lo masculino y lo femenino. La primera operación consiste en la promoción de identificaciones entre el sexo biológico y uno de los principios masculino o femenino con el consiguiente rechazo del principio contrario, dando lugar a la idea de que los hombres deben llegar a ser masculinos y las mujeres femeninas. La identificación entre el sexo biológico del macho y el principio masculino así como la correspondiente alienación y rechazo del principio femenino es lo que deviene en el género masculino y la identidad como hombre. La identificación entre el sexo biológico de la hembra y el principio femenino así como la correspondiente alienación y rechazo del principio masculino es lo que deviene en el género femenino y la identidad como mujer. La segunda operación consiste en la valoración diferencial de los principios masculino y femenino introduciendo inequidad valorativa de carácter arbitrario. Lo masculino se califica como positivo y de
} 
de valor cultural que privilegia los rasgos asociados con el hombre y "lo masculino" al tiempo que devalúa lo codificado con la mujer y "lo femenino"; en el heterosexismo: la construcción autoritaria de normas culturales que privilegian y promueven la heterosexualidad; y en la homofobia: la devaluación cultural de la homosexualidad que lleva al desprecio de las personas LGTBIQ.

Tal injusticia simbólica contra el sector LGTBIQ, está expresada materialmente en un no reconocimiento pleno a nivel político, jurídico y social, que ha sido resuelto con insuficiencia por el paradigma democrático liberal imperante. Esta injusticia simbólica es la base de la violencia simbólica que sufre el sector LGTBIQ, asociada con la negación, la exclusión social y la invisibilización que ha sido estudiada y denominada como la dominación simbólica contra los homosexuales por el sociólogo y filósofo francés Pierre Bourdieu:

La forma especial de dominación simbólica que sufren los homosexuales, afectados por un estigma que, a diferencia del color de la piel o la feminidad, puede estar oculto (o exhibido) se impone a través de los actos colectivos de categorización que hace que existan unas diferencias significativas, negativamente marcadas, y a partir de ahí unos grupos, unas categorías sociales estigmatizadas. $\mathrm{Al}$ igual que en algunas formas de racismo adopta en este caso la forma de una negación de la existencia pública y visible. La opresión entendida como "invisibilización" se traduce en un rechazo de la existencia legítima y pública, es decir, conocida y reconocida, especialmente por el derecho, y una estigmatización que solo aparece tan clara cuando el movimiento reivindica la visibilidad. Entonces se le recomienda explícitamente la "discreción" o el disimulo que habitualmente se ve obligado a imponerse (2000: 143-144).

Estos actos colectivos de categorización de los cuales nos habla Bourdieu están basados en la cultura patriarcal ("sociedad androcéntrica" para Bourdieu) que ha marcado históricamente no sólo la discriminación y exclusión de las personas LGTBIQ, sino también la violencia simbólica generalizada y ancestral. Esta violencia de corte patriarcal está íntimamente relacionada con la fuerza, la agresividad, el autoritarismo, la necesidad de control, las oposiciones binarias, la negación del otro diferente y su consiguiente aniquilación, ya sea física o simbólica. En el fundamental texto citado de Bourdieu, el pensador concluye que

mayor valor que lo femenino, que se califica como negativo y de menor valor. Lo masculino es motivo de orgullo y lo femenino de vergüenza. Lo masculino es bueno y lo femenino es malo, etc. La tercera operación se refiere al ejercicio de poder desde el principio masculino sobre el principio femenino. Desde este punto de vista los hombres deben gobernar sobre las mujeres o cualquier aspecto femenino debe estar subordinado a lo masculino. La razón debe dominar a las emociones, al placer o a lo irracional, etc. El símbolo del poder masculino se concreta en la imagen del padre o patriarca y se expresa en términos de relaciones de pertenencia o propiedad. Sobre la base de este sistema de distinciones y las operaciones mencionadas se han regulado las relaciones sociales de tal manera que se ha configurado la estructura social y cultural conocida como patriarcal” (2006: 20). 
la base de la dominación masculina anclada en la cultura o tradición patriarcal ${ }^{4}$ (sociedad androcéntrica) está en los procesos responsables de la transformación de historia en naturaleza que han hecho de la diferencia - contingente, cultural y arbitraria - entre masculino y femenino una necesidad sociológica naturalizada. De esta manera se ha erigido en esencia natural lo que no es más que un proceso de construcción histórica, se ha "transformado la historia en naturaleza y la arbitrariedad cultural en natural":

Recordar que lo que, en la historia, aparece como eterno sólo es el producto de un trabajo de eternización que incumbe a unas instituciones (interconectadas) tales como la Familia, la Iglesia, el Estado, la Escuela, así como en otro orden el deporte y el periodismo (siendo estos conceptos abstractos simples designaciones estenográficas de mecanismos complejos que tienen que analizarse en algún caso en su particularidad histórica), es reinsertar en la historia, y devolver, por tanto, a la acción histórica, la relación entre los sexos que la visión naturalista y esencialista les niega (Bourdieu, 2000: 8).

Con la filósofa Judith Butler, el acento sobre la exclusión y la discriminación a las personas LGTBIQ se pone en los discursos hegemónicos sobre la sexualidad circundante en la sociedad, en lo que esta autora norteamericana denomina matriz discursiva de heterosexualidad obligatoria. Para Butler, la abyección de las personas LGTBIQ se da en términos de su ininteligibilidad para quienes esperan que haya una coherencia entre sexo anatómico (hombre-mujer), género (masculino-femenino) y orientación sexual (hetero). En otras palabras, la existencia de estos seres abyectos no se entiende, no se considera posible, produce la extrañeza de algo anormal, insólito, incomprensible. Es decir, estos seres producen rechazo y repudio porque al subvertir la norma sexual retan la legitimidad de la construcción heterosexual hegemónica, atentan contra la construcción colectiva del poder y trastocan los referentes de normalidad existentes. Asimismo, es preciso resaltar que Butler retoma la idea derridiana de "exterior constitutivo" que, en pocas palabras, nos dice que se requiere la existencia de otros (anormales, abyectos, ininteligibles) para que se constituya un nosotros (normales, inteligibles):

Si se comprende la restricción como restricción constitutiva, aún es posible formular la siguiente pregunta crítica: ¿cómo tales restricciones producen, no sólo el terreno de los cuerpos inteligibles, sino también un dominio de cuerpos impensable, abyectos, invivibles? La primera esfera

${ }^{4}$ Tal tradición se reproduce en las instituciones fundamentales de la sociedad: Familia (eje básico privado de la reproducción y la visión androcéntrica), Escuela (eje básico social de la reproducción del statu quo patriarcal), Iglesia (eje básico social y reforzador simbólico de la visión antifemenina, misógina y homofóbica), Estado (eje regulador social, jurídico y normativo de tal statu quo patriarcal). 
no es lo opuesto de la segunda, porque las oposiciones son parte de la inteligibilidad; la última esfera es el terreno excluido, ilegible, que espanta al primero como el espectro de su propia imposibilidad, el límite mismo de su propia inteligibilidad, su exterior constitutivo (Butler 1993: 14).

Para terminar y a manera de balance final de esta parte, diré que la fobia hacia el sector LGTBIQ está íntimamente ligada con la subversión que plantea este inmenso colectivo humano de los roles sexuales, reproductivos y de género por medio de su interpelación vital a la legitimidad de la construcción heterosexual hegemónica y con su interpelación política en contra la construcción colectiva del poder e institucionalidad patriarcal. Pasaré ahora a exponer con mayor detenimiento las respuestas políticas y el papel que juegan en la problemática asociada al reconocimiento del sector LGTBIQ: (1) la política liberal, (2) el paradigma de la política de la diferencia o de la identidad y (3) la política de la transformación cultural o de la deconstrucción de las identidades.

\section{El papel del paradigma liberal con respecto al sector LGTBIQ}

En primer lugar, es preciso ubicar cronológicamente la discusión actual sobre el reconocimiento social, político y jurídico del sector LGTBIQ en sociedades democráticas liberales, dado lo mucho que la sociedad democrática occidental debe a la tradición liberal moderna. Esta discusión ni siquiera es planteada a nivel académico en sociedades cerradas o de carácter confesional. Históricamente la lucha por la tolerancia, la defensa de las libertades individuales, la defensa contra la interferencia del Estado en la esfera privada y a favor del pluralismo ha estado relacionada con la lucha por el establecimiento de la democracia liberal en las sociedades occidentales. Los liberales pusieron sobre la palestra de la filosofía política la cuestión de la igualdad de derechos, la autonomía, las libertades básicas y el respeto por la diferencia.

Modernamente, autores como John Rawls, Ronald Dworkin y Jürgen Habermas, entre otros, han continuado la tradición liberal haciendo énfasis en las libertades políticas básicas, la autonomía individual, el pluralismo ideológico y la neutralidad del Estado, y han integrado tales nociones al concepto moderno de justicia. Así, el principio básico que definiría a la filosofía liberal moderna podría sintetizarse esquemáticamente en la siguiente fórmula: el liberalismo es la teoría política que independiza el contenido de la justicia de cualquier noción o teoría particular de la vida buena, de la virtud y de la excelencia bumana. Este principio conlleva una necesidad de carácter lógico o una teoría de los valores: no se puede probar racionalmente que una creencia o cosmovisión es más válida que otra. Esto implica la imposibilidad de juzgar por la prevalencia de determinados fines. De 
esta forma, en política no existe la "Verdad", existen acuerdos: todas las verdades son acuerdos intersubjetivos. La política no se trataría entonces de la búsqueda de la verdad sino de la búsqueda de acuerdos para la convivencia.

Es en este sentido que, según Dworkin, podemos entender la aspiración moderna del pluralismo liberal, que no es un relativismo ni un escepticismo ya que no supone que diferentes respuestas o ninguna sean correctas a la pregunta por los fines de la vida y la excelencia humana, sino que afirma que el Estado no puede responder por todos y cada uno de los individuos y que hacerlo sería menospreciar su dignidad y el libre desarrollo de su individualidad. Este es uno de los principios esenciales de la filosofía liberal: separar la moral colectiva, que son las normas requeridas para una convivencia social, de la moral individual, que es el ejercicio pleno de la libertad, donde el único límite a la acción individual lo constituye el derecho y la capacidad que tienen los demás a ejercer su propia individualidad.

En este orden de ideas, los presupuestos teóricos de la filosofía liberal, que a grandes rasgos han sido expuestos, sientan las bases para una respuesta del Estado moderno liberal a la aspiración de justicia y reconocimiento del sector LGTBIQ. Así, para los liberales el problema del reconocimiento de este sector poblacional se soluciona apelando a los derechos a la privacidad, al libre desarrollo de la personalidad y a la tolerancia, es decir, la cuestión se soluciona privatizando la vida sexual y los acuerdos de tales individuos. Asimismo, para los liberales la irrupción de esta problemática se puede explicar debido a la insuficiencia del proceso de liberalización de la sociedad en cuestión, esto es, el meollo del asunto sería trabajar en pos de su total liberalización. En algunos casos se propone dar respuesta a tal problemática haciendo ajustes de corte procedimental y reformista en los niveles jurídico y político del modelo liberal, por ejemplo con el uso de la acción afirmativa y/o la ley de cuotas.

Para efectos de nuestro análisis, creo que surgen varias preguntas sobre esta lectura liberal: ¿Qué están dejando por fuera los liberales? ¿Acaso creen a pie juntillas en la neutralidad del Estado? ¿Asumen que basta con levantar restricciones legales para terminar con el problema de la discriminación y la exclusión? ¿No reconocen el hecho de que al privatizar la sexualidad, la despolitizan? ¿Suponen que con el tiempo y sin apoyo diferenciado de orden jurídico-legal, el sector LGTBIQ logrará respeto y reconocimiento? ¿Cómo asumen el problema relacionado con las normas culturales informales de discriminación y exclusión?

Asimismo, considero que esta particular lectura liberal del asunto en cuestión también confunde o pasa por alto dos conceptos en dos planos distintos: el 
concepto de pluralismo ideológico (plano epistemológico) y el concepto de diversidad humana (plano ontológico). Una cosa es tener cierto tipo de creencias (las cuales se me pueden haber impuesto, o de las cuales puedo hacer proselitismo, o de las cuales puedo descreer o abjurar) y otra completamente distinta es ser un tipo de humano particular. Así, las personas del sector LGTBIQ no escogieron su orientación sexual ni su identidad de género, así como tampoco pueden decidir cambiarla el día de mañana: su deseo — aún por razones que no alcanzamos a comprender- se ha constituido, se ha impuesto y no se puede cambiar a voluntad. En otras palabras, no se escoge ser homosexual en una gama o menú de posibles elecciones, pero sí se puede escoger creer o no creer en un partido, creer en una o más deidades o en una institución, por más que se diga y se repita que su identidad está construida por tales creencias o esencias. Por ejemplo, no se nace "católico", se nace entre "católicos" que te impondrán tal creencia, pero sí se puede nacer homosexual entre heterosexuales.

En este punto considero acertado retomar la clásica crítica al individualismo liberal para leerla en clave del debate que nos interesa. Recordemos que al liberalismo se le reprocha su doctrina individualista que hunde sus raíces en la existencia de un yo presocial, totalmente formado antes de su confrontación con la esfera social. Así, el sujeto liberal se considera más como individuo autoconstruido que como sujeto social interdependiente y a partir de aquí emana su visión de los derechos como a-históricos y universales. Ahora bien, ¿cuál es la visión del liberalismo sobre el papel central de la cultura en la formación del sujeto? ¿Se autoconstruye el sujeto independiente de sus determinaciones culturales? ¿Se construye el homosexual o el heterosexual a partir de una elección conciente desde un vacío simbólico? Concomitante con esta crítica aparece la crítica a la visión universalista y racionalista del sistema liberal. Esta crítica afirma que no existe tal ilusión de universalidad preestablecida, que en el caso de Habermas presupone el acto de habla como rasgo racional del ser humano y en el caso de Rawls presupone la racionalidad y razonabilidad de los actores políticos. Esta es la crítica a la suposición de que el terreno político está compuesto por seres racionales, que a su vez sienta sus cimientos en presupuestos universales basados en una idea siempre (y paradójicamente) vacía e incompleta.

Entonces, como vimos al principio, los liberales defienden al sujeto con independencia de sus circunstancias, pero el problema parece estar precisamente en tales circunstancias, en anquilosadas creencias, normas e instituciones que no permiten el reconocimiento pleno y el respeto de las personas LGTBIQ en la democracia liberal. 


\section{El papel del paradigma de la política de la diferencia}

Si la política liberal promueve derechos universales indiferenciados para todos los seres humanos, la política de la diferencia o de la identidad reclamará derechos diferenciados basados en identidades particulares y subrayará el reconocimiento de tales diferencias e identidades como base de la reclamación por la exclusión y discriminación que grupos, minorías y sectores han sufrido históricamente en el marco de sociedades liberales. Así, existe un grupo de autores y autoras que han propuesto modelos alternativos a los fundamentos de la teoría liberal para dar respuesta a los grupos, sectores y minorías negativamente diferenciados. Tales autores y autoras hacen parte del moderno paradigma del reconocimiento de las identidades y de las diferencias que, además de plantear la necesidad de otorgar derechos diferenciados, cuestiona la idea clásica de igualdad, en particular la noción liberal abstracta de ciudadano, además de la aspiración a la neutralidad y la reivindicación de la tolerancia como camino a la igualdad. A continuación pasaré a exponer los planteamientos básicos de dos autores centrales del paradigma político de la diferencia: el filósofo canadiense Charles Taylor y la filósofa norteamericana Iris Marion Young. También expondré, a manera de ilustración, la propuesta intermedia de derechos para las minorías del liberal canadiense Will Kymlicka.

En su texto El multiculturalismo y la politica del reconocimiento, Charles Taylor ofrece una perspectiva filosófica con fundamentos históricos acerca de lo que está en juego en las peticiones hechas por muchos sectores y minorías negativamente discriminadas (en especial para las culturas étnicas y las minorías nacionales) para que las instituciones liberales modernas les reconozcan su particular identidad de grupo. Para comenzar, Taylor, con base en la Fenomenología del Espíritu de G. F. W. Hegel, expone el reconocimiento como una necesidad vital y exigencia fundamental del ser humano:

El no reconocimiento o el reconocimiento equivocado puede ser una forma de opresión, que aprisiona a la persona en un modo de ser falso, distorsionado, reducido. Más allá de la simple falta de respeto, puede infligir una herida grave, que agobia a las personas con un menosprecio de sí mismas que las inhabilita. El debido reconocimiento no es simplemente una cortesía sino una necesidad humana (Taylor ,1995: 293).

Luego de presentar esta cara moral del no reconocimiento debido a una persona, el autor canadiense compara dos formas de gobierno que compiten entre sí: una que no protege a ninguna cultura o grupo en particular pero que garantiza los derechos y el bienestar de todos sus ciudadanos, fundamentada en la idea de la igual dignidad humana, y otra fundamentada en una política de la diferencia, 
que impulsa una cultura incluyente de carácter multiculturalista protectora de los derechos fundamentales y el bienestar de los sectores inconformes de ciudadanos colectivamente identificados. Taylor resalta el hecho de que el liberalismo termina convirtiéndose en un credo combatiente que intenta imponer su cultura política a otros. Para el autor, es una exigencia liberal imposible pedirle a ciertos grupos que hablen el lenguaje de la ciudadanía ("ciudadanes") para exigir y reclamar sus derechos, ya que en este proceso perderían parte de su identidad colectiva que les da sentido y vida. Para el autor el liberalismo falla, entonces, a su promesa de tratar a todas y todos por igual y de ser imparcial ante las diferencias. Taylor culmina su texto haciendo un llamado a la noción gadameriana de "fusión de horizontes" para que el proceso de reconocimiento de las identidades y culturas particulares sea, dentro del paradigma liberal, una realidad.

Para culminar, esta presentación de las ideas básicas de Taylor, deseo llamar la atención sobre la crítica o respuesta que da el autor en su ensayo a los que él denomina neonietzscheanos deconstruccionistas y que identifica principalmente con dos autores franceses: Foucault y Derrida. Estos autores, como veremos más adelante, constituyen gran parte de la base teórica de la política de la transformación cultural o de la deconstrucción de las identidades.

[Para los neonietzscheanos deconstruccionistas] todo juicio de valor se basa en normas que en última instancia fueron impuestas por estructuras de poder que, además, las confirman (...) el asunto se convierte en una cuestión de poder y contrapoder: ya no se trata de respeto y búsqueda de reconocimiento sino de tomar partido, de solidaridad (Taylor, 1995: 103).

De esta manera, para Taylor, la propuesta deconstruccionista desarticula la lucha por la búsqueda de reconocimiento y respeto y queda reducida a una lucha agonística de un poder contra otro poder en la cual sólo resta tomar partido: ser cómplice o solidario. En otras palabras, se reduce el asunto de la lucha por el reconocimiento finalmente a dos opciones: la victoria sobre los dominadores y opresores o la tolerancia servil a sus prácticas.

De otra parte, Iris Marion Young, en su texto La justicia y lapolítica de la diferencia sustentado en la teoría crítica de la sociedad, da una respuesta a la teoría liberal de la justicia rawlsiana. La autora centra su atención no en la forma de hacer justicia sino en las formas existentes de injusticia, no sólo económicas sino además simbólicas y culturales. Young, al igual que Taylor, reivindica la idea de reconocer las identidades colectivas de los grupos diferenciados y contextualizar la justicia de acuerdo a las particularidades de tales grupos, minorías y culturas (grupos sociales). A diferencia de Taylor, Young hace un llamado a no centrarnos en la 
redistribución y sus ideas adyacentes de igualdad de oportunidades, imparcialidad, igualdad formal jurídica y subjetividad moral como fundamento de las teorías de la justicia, sino en los conceptos de dominación y opresión expresados por los grupos excluidos sobre la participación en la toma de decisiones, la expresión cultural de la diferencia y la división del trabajo:

La justicia no debería referirse sólo a la distribución, sino también a las condiciones institucionales necesarias para el desarrollo y ejercicio de las capacidades individuales, de la comunicación colectiva y la cooperación. Bajo esta concepción de la justicia, la injusticia se refiere principalmente a dos formas de restricciones que incapacitan: la opresión y la dominación. Estos impedimentos incluyen modelos distributivos, pero también implican cuestiones que no pueden asimilarse sin más a la lógica de la distribución: procedimientos de toma de decisiones, división del trabajo y cultura (Young, 1990: 72).

En esta forma, para Young la opresión que sufren ciertos sectores y minorías negativamente discriminadas puede entenderse en términos de lo que ella denomina sus cinco caras: explotación, marginación, carencia de poder, imperialismo culturaly violencia. Para la autora es necesario reconocer los múltiples grupos y sectores que conforman la sociedad moderna y justifica las políticas de acción afirmativa, pues son un poder contra-hegemónico ideal para socavar la opresión que viene determinada por el legado cultural, los prejuicios, hábitos y conductas que privilegian a los hombres blancos heterosexuales y excluyen a otros grupos sociales:

En los últimos años, feministas, activistas de los movimientos de la liberación de la gente negra, indígenas, gente discapacitada y otros grupos oprimidos, al ser catalogados como cuerpos temerosos, han reafirmado tales imágenes de diferencia positiva. Tales movimientos han cuestionado el ideal de liberación entendido como la eliminación en la vida política e institucional de las diferencias de grupo (...) (Yo) defiendo, en cambio, principios y prácticas que identifican la liberación con la igualdad social que afirma las diferencias de grupo y promueve la inclusión y la participación de todos los grupos en la vida pública (Young ,1990: 25).

Para la autora, una de las razones fundamentales para conceder derechos diferenciados a los grupos o sectores oprimidos tiene que ver con el hecho de que los privilegios sociales y económicos de los grupos hegemónicos suponen, entre otras cosas, que estos sienten que tienen el derecho de hablar, opinar y ser escuchados como si tuvieran un derecho superior, dado por sus recursos materiales y organizativos, por encima de las minorías. Por esta razón, para Young es imprescindible y urgente que los citados grupos oprimidos logren una representación explícita y diferenciada en las discusiones y en la toma de 
decisiones.

Existe una crítica contundente a la teoría política de Young, planteada por Will Kymlicka, que apunta a lo desarticulante e inmovilizadora de su propuesta. Según este autor, Young al referirse a los grupos sociales oprimidos (en el caso de Estados Unidos, ejemplo más cercano a su contexto) se está refiriendo aproximadamente al $80 \%$ de la población:

En la actualidad, en los Estados Unidos, sufren una o más forma de opresión al menos los siguientes grupos: las mujeres, los negros, la población autóctona originaria, los chicanos, los puertorriqueños y otros estadounidenses de habla hispana, los estadounidenses de origen asiático, los gays, las lesbianas, la clase obrera, los pobres, los ancianos y las personas física y mentalmente discapacitadas (Kymlicka, 2000: 202).

Así, de acuerdo a Kymlicka, la autora parece estar haciendo peticiones de derechos para casi todos los ciudadanos y ciudadanas estadounidenses a excepción de los "hombres blancos heterosexuales acomodados, sanos y jóvenes" sin tomar en cuenta dos hechos fundamentales: derechos colectivos diferenciados para todos estos grupos sociales terminan siendo unos derechos colectivos impracticables e irrealizables para ninguno y, muy especialmente (asunto fundamental sobre el cual volveré), esta idea deja por fuera las opresiones entrecruadad o el sobrecruaamiento de opresiones. Por ejemplo, ¿qué tipo de derechos colectivos reclamaría una mujer inmigrante, negra, pobre, perteneciente a la clase obrera, indocumentada y lesbiana?

En síntesis, para estos autores partidarios de alguna variación de la política de la diferencia y críticos de las insuficiencias del universalismo igualitario liberal, aún si la sociedad se liberalizara por completo - ideal de progreso para los liberales - seguiría sin reconocer a tales grupos humanos porque no lograría reconocerlos como sus miembros desean o esperan que los reconozcan, sino como el liberalismo los reconoce, es decir, como iguales indiferenciados. En otras palabras, los miembros de tales grupos no están exigiendo reconocimiento como iguales — que sería una de las formas de asimilarlos — sino reconocimiento como diferentes.

Nuevamente y para efectos de nuestra reflexión, creo que surgen varias preguntas sobre esta lectura desde la política de la diferencia o de la identidad: ¿Qué están dejando por fuera sus partidarios? ¿Qué responden ante el reclamo liberal sobre la cosificación o esencialización de las identidades? ¿No están concediendo un privilegio para un cierto grupo humano que sería igualmente discriminatorio con el resto de la comunidad política? ¿Al sobrevalorar las identidades particulares y grupales, no están abriendo las puertas para que 
cualquier colectividad pueda pedir derechos particulares, por ejemplo, los pedófilos o los necrófilos o los zoófilos, que sienten históricamente vulnerados sus derechos a la libre expresión sexual, o los neo-nazis o partidarios del $\mathrm{Ku}$ Klux Klan que sienten históricamente vulnerados sus derechos a la libre expresión política? ¿Este refuerzo y valoración de las identidades no está igualmente reforzando los estereotipos históricamente excluyentes y dogmáticos: hétero-homo, normal-anormal, hombre-mujer? ¿No estarán de esta manera reivindicando una identidad que puede estar al servicio de la opresión y la dominación denunciadas? ¿Cuál es su postura ante las opresiones entrecruzadas o el sobrecruqamiento de opresiones?, o en palabras de Judith Butler:

Los levantamientos de esclavos que insisten en la autorización universal de la emancipación adaptan un discurso que corre por lo menos un doble riesgo: el esclavo emancipado puede ser liberado dentro de un nuevo modo de sujeción que la doctrina ciudadana tiene reservado y esa doctrina puede encontrarse conceptualmente rasgada precisamente por los reclamos emancipatorios que ella ha a hecho posible (Butler et al., 2003: 47).

Como balance final, considero que la política de la diferencia no responde acertadamente a las críticas que se le formulan desde otras teorías políticas como el liberalismo y la política de la transformación cultural. Los asuntos citados relacionados con la reificación de las identidades, el separatismo, la erosión de los derechos humanos fundamentales y las opresiones entrecruzadas basadas en imaginarios culturales discriminatorios y anquilosados, sufridas por seres reales en contextos reales, quedan aún sin responder.

A renglón seguido presentaré la perspectiva de reconocimiento desde el ámbito de la política de la transformación cultural o de la deconstrucción plena de las identidades, asociada con la perspectiva teórica-crítica, radical crítica a la propuesta política liberal y a la salida de la política de la diferencia.

\section{El papel del paradigma teórico-crítico queer: la política de la transformación cultural}

En primer lugar es preciso aclarar que son varias las autoras que se podrían inscribir en la que he denominado "política de la transformación cultural o de la deconstrucción de las identidades" (entre ellas Donna Haraway y Teresa de Lauretis) y que hacen parte de los presupuestos conceptuales de la actualmente denominada teoría crítica queer, fundamento a su vez, del movimiento político queer. Empero, dada su relevancia filosófica actual, he decidido centrarme 
fundamentalmente en los planteamientos de la filósofa postfeminista, postestructuralista y posmodernista Judith Butler (1956, Cleveland, E.E.U.U) sobre la teoría performativa del género y la identidad.

En síntesis, la citada teoría crítica queer apunta a desmantelar tanto la concepción de sujeto/a universalista que sustenta la filosofía liberal, como los procesos de esencialización, naturalización e identificación de las teorías de la política de la diferencia o de la identidad en relación con el sector LGTBIQ. Así, la orientación sexual, la identidad sexual o la expresión de género son el resultado de una construcción social, histórica y cultural, y por lo tanto no existen papeles sexuales o roles de género esencial o biológicamente inscritos en la naturaleza humana. Es decir, la única naturaleza humana es la cultura. Para la teoría crítica queer el/la sujeto/a perteneciente al sector LGTBIQ (sujeto/a innombrable, abyecto, anormal) es el efecto y resultado de la producción de una red de dispositivos de saber/poder que se explicitan en las actuales concepciones esencialistas imperantes sobre el género y la diferencia sexual. De esta forma, el género y el sexo son actuaciones, actos performativos que son modalidades del discurso autoritario. Tal performatividad alude al poder del discurso para realizar aquello que enuncia y por lo tanto permite reflexionar acerca de cómo el poder hegemónico heterocentrado actúa como discurso creador de realidades socioculturales. En este sentido y en la línea foucaultiana puede entenderse la performatividad del lenguaje como una tecnología, como un dispositivo de poder social y político:

Si el lenguaje o el discurso de la subjetividad ha tenido por efecto la creación del yo -la creencia de que existe un yo a-priori o anterior al lenguaje-, el discurso sobre la sexualidad ha creado las identidades sexuales y de género (Mérida, 2002: 12).

En las siguientes dos frases de otra importante y actual teórica queer, Beatriz Preciado, en su exposición de la obra de Butler, podría condensarse el planteamiento crítico central de esta teoría:

El género y la diferencia sexual no tiene estatuto ontológico fuera de los actos que lo constituyen. [...] El género y la diferencia sexual son el efecto retroactivo de la repetición ritualizada de performances. ${ }^{5}$

Así el género y la diferencia sexual son una ficción cultural fruto del efecto performativo de una repetición ritualizada de actos que acaban naturalizándose y produciendo la ilusión de una sustancia. Como ejemplo de esto podemos pensar

Entrevista a Beatriz Preciado por Jesús Carrillo. En: www.arteleku.net/4.0/pdfs/preciado. pdf (pág. 5) 
en las prácticas de crianza occidentales, en las cuales desde su nacimientoel niño tiene un lugar y un papel determinado en el mundo: su ropa será azul, sus juegos estarán relacionados con la fuerza, la competencia y el poder (armas, carros, fútbol, caballos de madera, etc.), tendrá menos restricciones en su movimiento (no usará vestidos largos e incómodos, faldas ni sandalias que por ejemplo le impidan subir a un árbol), el trato de los hombres de la casa hacia él tendrá cierto nivel de fuerza y temple y, por supuesto, se le prohibirá en lo posible llorar ("los hombres no lloran") o ser "afeminado" (maquillarse, jugar con muñecas o con utensilios de cocina). Por consiguiente, para la teoría crítica queer, el/la sujeto/a excluido/a, innombrable, abyecto/a, anormal es el efecto de la producción de una red de dispositivos de saber/poder, que Judith Butler, en términos modernos y apoyándose en el citado concepto lingüístico de enunciado performativo de John Austin, caracterizará como sigue:

El "sujeto" es el resultado del proceso de subjetivación, de interpretación, de asumir performativamente alguna "posición fija del sujeto" [...] por esto el fracaso de cualquier articulación en particular para describir a la población que representa dada la "incompletitud" de cualquier posición del sujeto $[\ldots]$ Tú me llamas así, pero lo que yo soy elude el alcance lingüístico de cualquier esfuerzo específico por captarme (Butler et al., 2003: 15, 38).

Aparece entonces en este punto un giro conceptual fundamental para la política de la igualdad liberal y para la política de la diferencia: ya no estamos en los terrenos de la búsqueda de aceptación social, tolerancia y su consabida respuesta llamando a la privatización y a la discreción, o haciendo un llamado a la concesión de derechos al mal llamado "grupo" o a la mal llamada "comunidad" LGTBIQ. Nos encontramos en cambio en los terrenos de la deconstrucción simbólica y de la desnaturalización de las diferencias sexuales y de género, con el objetivo de sacar a la luz los numerosos estratos que operan en el discurso hegemónico. En palabras de Judith Butler:

Las cuestiones que estarán en juego en la reformulación de la materialidad de los cuerpos serán: (1) la reconsideración de la materia de los cuerpos como el efecto de una dinámica de poder, de modo tal que la materia de los cuerpos sea indisociable de las normas reguladoras que gobiernan su materialización y la significación de aquellos efectos materiales; (2) la comprensión de la performatividad, no como el acto mediante el cual un sujeto da vida a lo que nombra, sino, antes bien, como ese poder reiterativo del discurso para producir los fenómenos que regula e impone; (3) la construcción del "sexo" no ya como un dato corporal dado sobre el que se impone artificialmente la construcción del género, sino como 
una norma cultural que gobierna la materialización de los cuerpos; (4) una reconcepción del proceso mediante el cual un sujeto asume, se apropia, adopta una norma corporal, no como algo a lo que estrictamente se somete, sino, más bien, como una evolución en la que el sujeto se forma en virtud de pasar por ese proceso de asumir un sexo; y (5) una vinculación de este proceso de "asumir" un sexo con la cuestión de la identificación y con los medios discursivos que emplea el imperativo heterosexual para permitir ciertas identificaciones sexuadas y excluir y repudiar otras (Butler ,1993: 19).

De aquí que, para la teoría crítica queer, la lucha por el reconocimiento político, jurídico y social del sector LGTBIQ no sería una lucha de carácter identitario, tampoco una lucha por la normalización o el reclamo de tolerancia -se tolera lo que no se soporta, lo que no se desea que exista: se tolera el dolor, la guerra, la enfermedad, etc.-, sino una lucha por el respeto pleno - se respeta a lo que se le concede calidad de digno, a lo que se le reconoce como respetable -, por el reconocimiento de la diferencia y la diversidad sexual-derecho a la diferencia, no diferencia de derechos- y por su desnaturalización: posiblemente una lucha ardua y prolongada por la construcción de un nuevo orden simbólico. Es por esto que en el existente circuito interconectado de opresiones y exclusiones se podría revindicar para los seres humanos las identidades móviles, teatrales, transversales o paródicas. En palabras del investigador colombiano Manuel Velandia, se puede definir tentativamente la identidad como:

La idea y la sensación móviles que tiene el ser humano, en una sociedad y tiempo concretos, de ser lo que busca ser con relación a la cultura, a los otros/as seres de su entorno y consigo mism@, y de seguir siéndolo en el transcurso del tiempo (Velandia, 2006: 10).

O también, en palabras de la profesora Gabriela Castellanos:

Desde una perspectiva crítica lo humano puede ser visto como diverso, precisamente por que es una especie de diálogo entre naturaleza y cultura, entre el mundo físico y el mundo social y cultural [...] No tenemos una "identidad" fija e innata, sino que "ponemos en juego una identidad" cuando realizamos determinados actos de habla [...] Lo humano es precisamente la posibilidad de invocar identidades en distintos momentos a partir de un cierto repertorio más o menos estable y al mismo tiempo más o menos fluctuante a lo largo de la vida (Castellanos, 2004: 28-29).

Es por tal razón que en filosofía política, para definir las categorías del sector LGTBIQ, usamos los términos “orientación sexual” en vez de "identidad sexual”, “expresión de género" en vez de “identidad de género”. Estas categorías pretenden unificar un colectivo pero al mismo tiempo des-esencializarlo, des-identificarlo. 
Es en esta línea que, según la teoría crítica queer, para el sector LGTBIQ la tarea no se trataría sólo de luchar por la ampliación de derechos (matrimonio, adopción, patrimonio, etc.), de luchar por "correr la cerca", sino por la deconstrucción del orden simbólico, ya que lo opuesto puede producir un ensanchamiento de la brecha ya existente entre formas legítimas e ilegítimas del intercambio sexual y de la expresión de género.

[...] esto sucede cuando pensamos que hemos encontrado un punto de oposición a la dominación y luego nos damos cuenta de que ese punto mismo de oposición es el instrumento a través del cual opera la dominación, y que sin querer hemos fortalecido los poderes de dominación a través de nuestra participación en la tarea de oponernos. La dominación aparece con mayor eficacia precisamente como su "otro" (Butler et al., 2003: 34).

Para la teoría crítica queer, el derecho contribuye y refuerza el orden discursivo heterocentrista. Aún cuando el derecho en las sociedades liberales no sea en muchos casos una fuente explícita de discriminación y exclusión, sí es en la mayoría de los casos un reflejo, un reproductor del debate que se da en otros campos de la sociedad y que representa, como expresaba más arriba, la voluntad de la ideología dominante elevada a categoría de ley. En nuestro caso colombiano es fundamentalmente el reflejo de la moral cristiana, que como se puede corroborar en los debates por el reconocimiento del sector LGTBIQ en el Congreso, representan la base de casi la totalidad de los argumentos de los senadores opositores. De tal suerte, si asumimos con la teoría crítica queer el hecho de que el sexo y el género son culturalmente construidos e históricamente situados, las categorías dicotómicas de "femenino", "masculino", "heterosexual" y "homosexual" se pueden entender como repetición de actos performativos en lugar de valores naturales, innatos.

En este orden de ideas, para la teoría crítica queer es imperativo deconstruir todas las categorías binarias de la lógica de la dominación: bueno/malo, bello/ feo, normal/anormal, blanco/negro, hétero/homo, gay/lesbiana. De igual manera, es también imperativo deconstruir el heterocentrismo - parte esencial del orden simbólico imperante - que es el discurso normativo hegemónico que modela los cuerpos y prescribe implícitamente el deber ser erótico-sexual de el/la sujeto/a, de el/la otro/a. El fin último no es fortalecer o solidificar ningún tipo de identidad sino deconstruir las dicotomías citadas con el fin de desestabilizar todas las identidades fijas, para así propiciar la emergencia de diferencias múltiples, no binarias, cambiantes, móviles. En términos de Derrida, crear las condiciones para la emergencia de la differance opuesta a la difference o, en términos de Deleuze y Guattari, la emergencia de las identidades nómadas. 
El trabajo crítico-filosófico queer consistiría inicialmente en deconstruir tales categorías sobre las que se funda lo abyecto, el discurso de la normalidad y su concomitante discurso sobre la moralidad:

La tarea será no asimilar lo indecible al dominio de lo decible para albergarlo allí, dentro de las normas de dominación existentes, sino destruir la confianza de la dominación, demostrar qué equívocas son sus pretensiones de universalidad y, a partir de esa equivocación, seguir la ruptura de su régimen, una abertura hacia versiones alternativas de universalidad que se forjen a partir del trabajo de traducción mismo (Butler et al., 2003: 18).

Es en este punto donde se hace un llamado, desde la teoría crítica queer a la resistencia y a la subversión. En palabras de Butler:

A diferencia de una visión que forja la operación de poder en el campo político exclusivamente en términos de bloques separados que compiten entre sí por el control de cuestiones políticas, la hegemonía pone el énfasis en las maneras en que opera el poder para formar nuestra compresión cotidiana y para orquestar las maneras en que consentimos (y reproducimos) esas relaciones tácitas y disimuladas del poder. Tal poder no es estable ni estático, sino que es reconstruido en diversas coyunturas dentro de la vida cotidiana; constituye nuestro tenue sentido de sentido común y está cómodamente instalado en el lugar de las epistemes prevalecientes de una cultura. Más aun, la transformación social no ocurre simplemente por una concentración masiva en favor de una causa, sino precisamente a través de las formas en que las relaciones sociales son rearticuladas y nuevos horizontes conceptuales abiertos por prácticas anómalas o subversivas (Butler et al., 2003: 19-20).

Es entonces, fundamental desde este enfoque crítico de la teoría queer, tratar de abrir puntos de fuga, de multiplicar los espacios de resistencia, de acción micropolítica y de generar alianzas estratégicas no esencialitas entre los otros tipos de exclusiones. En palabras de Leticia Sabsay, refiriéndose a Butler:

Como alternativa a estos proyectos de sesgo iluminista (liberalismo - política de la diferencia) su propuesta es la de proliferar, multiplicar las posiciones, explotar la diseminación de la diferencia. Y entiende que éste es realmente un proyecto transformador por cuanto la introducción de diferencia sería en sí misma desestabilizadora. La diferencia modificaría necesariamente las jerarquías ya que al introducir un nuevo significante en el sistema de representaciones (en la cadena del significante), todas las relaciones diferenciales y de valor (de los signos) se alteran (Sabsay, 2006: 15). 
No han sido pocas las críticas a la teoría performativa del género, base de la teoría queer. En particular, una de las más citadas y vehementes —que además recoge varias de las críticas de otros pensadores - es la que realiza la filósofa norteamericana Martha Nussbaum contra Judith Butler en el artículo "The Professor of Parody". En este escrito, Nussbaum acusa a la autora de ser una pensadora elitista de feminismo exclusivamente académico y de estilo autoritario, cuyo pensamiento — que otorga un papel preponderante al lenguaje — no puede dar cuenta de la realidad del sufrimiento y la opresión que experimentan seres humanos reales en tiempos y espacios reales. Además, Nussbaum afirma que la teoría política de Butler imposibilita la acción política y termina en un quietismo político que hace juego a la opresión que supuestamente intenta denunciar.

Para finalizar la exposición de esta teoría crítica deconstructora de las identidades deseo resaltar el hecho de la imposibilidad última de argumentar contra ella. Es decir, a pesar de exponer una valiosa crítica de la cultura occidental, esta aproximación radical gira en torno a un sistema cerrado contra el cual se hace casi que imposible la crítica racional y la contra-argumentación. Por tal razón creo que la crítica de Nussbaum (que es la misma crítica a los neo-nietzscheanos foucaultianos) tiene vigencia en el sentido de su cierre del universo de lo político. ¿Si todos mis contradictores están atravesados/as por los poderes inmanentes y trascendentes, de los cuales yo estoy plenamente conciente y denuncio, cómo llegar a un diálogo con ellos/as? Algo semejante a lo ocurrido con las respuestas dadas desde el marxismo dogmático a sus críticos, llamados revisionistas o reformistas o simplemente pequeños burgueses: "tienes tres opciones: estás con nosotros, estás contra nosotros o no has entendido el problema y tu papel histórico en la revolución". También creo interesante explicitar la autocrítica con respecto a la reivindicación del sujeto vacío que plantea la misma Judith Butler (y que queda sin respuesta) en el prefacio de 1999 a su texto, ya clásico, El género en disputa: feminismo y subversión de la identidad:

¿Cómo procedemos para hacer juicios acerca de cómo ha de vivirse el género con base en las descripciones teóricas que aquí se ofrecen? No es posible oponerse a las formas 'normativas' del género sin suscribir al mismo tiempo cierto punto de vista de cómo debería ser el mundo con género (Butler, 2001: 21).

Para concluir mi exposición de este modelo, diré que frente a la propuesta radical planteada por la salida deconstructivista de las identidades surgen varias preguntas. Las más obvias son: ¿Cómo va a lograrse la deconstrucción plena de todas las identidades existentes, por lo menos en el ámbito de lo sexual y del género? ¿Cuál es el control temporal y espacial de tal propuesta? ¿Cuándo se 
vacía totalmente de contenido el sujeto (des-identificación, des-esencialización)? ¿A partir de qué concepción o concepciones básicas se construirá el marco de referencia para oponer algo a lo que vamos a deconstruir? ¿ $\mathrm{O}$ no existe forma alguna de hablar de marco de referencia?

\section{La propuesta intermedia de Nancy Fraser y la construcción de la democracia radical}

Después de la presentación de las tres salidas políticas al debate que nos ocupa podemos preguntarnos: ¿De qué manera podrían conciliarse políticamente - si es que realmente puede existir tal conciliación- las salidas de corte procedimental/ progresivo, que hacen énfasis en la petición de derechos (política liberal y de la diferencia) y la salida de corte radical/transformativo que aboga por una transformación revolucionaria de la estructura cultural valorativa que desestabilizaría todas las identidades colectivas existentes? $\mathrm{O}$ en otras palabras, ¿cómo conciliar — en el caso de que sea posible - una crítica deconstructivista radical a nuestra cultura actual con una salida normativa moderada centrada en la exigencia de derechos fundamentales? Para intentar dar respuesta a la pregunta anterior recurriré a la propuesta de Nancy Fraser, quien en el texto Nuevas reflexiones sobre el reconocimiento (2002) presenta una salida alternativa al debate que nos ocupa, basada en el modelo del estatus. Desde mi punto de vista, ésta podría representar la respuesta más interesante y realista ante la exigencia de reconocimiento del sector LGTBIQ.

En síntesis, en el artículo mencionado Nancy Fraser desarrolla dos críticas fundamentales a los modelos o perspectivas políticas que he expuesto anteriormente (política de la diferencia y política de la transformación cultural). En primer término, Fraser afirma que la demanda de reconocimiento basada en la identidad está reemplazando y desplazando en la práctica la urgente demanda por la redistribución económica. En segundo término, la autora señala que la importancia desmedida que se le está dando a la valoración y reivindicación de las identidades particulares está dejando atrás la cuestión del estatus equitativo. Pasaré a ampliar estas dos ideas, exponiendo a grandes rasgos la totalidad del artículo y sus ejes principales, que para mis intereses argumentativos son centrales.

En la primera parte, la autora comienza exponiendo dos problemas centrales de la política del reconocimiento basada en el modelo de la identidad diferenciada: el problema del desplazamiento y el problema de la reificación. El problema del desplazamiento apunta al desplazamiento que se ha efectuado desde las luchas por la distribución hacia las luchas por el reconocimiento, lo cual está marginando las 
reivindicaciones a favor de la redistribución igualitaria en lugar de completarlas y enriquecerlas. Para la autora existen dos corrientes que terminan desplazando tales reivindicaciones redistributivas. Una de ellas ignora totalmente la injusticia de tipo económico, centrándose exclusivamente en iniciativas encaminadas a la transformación radical de la cultura. En este tipo de corriente se podría ubicar a la teoría crítica queer.

Para esta corriente, lo esencial del problema son los discursos que circulan libremente, no las significaciones y normas institucionalizadas. Al hipostasiar la cultura, simultáneamente abstraen la falta de reconocimiento de su matriz institucional y ocultan su entretejimiento con la injusticia distributiva. No logran comprender, por ejemplo, los lazos (institucionalizados en los mercados de trabajo) entre, por un lado las normas androcéntricas que infravaloran las actividades codificadas como "femeninas" y, por otro, los bajos salarios de las trabajadoras. Asimismo, pasan por alto los lazos institucionalizados que se dan en los sistemas de bienestar social, entre, de una parte, las normas heterosexistas que deslegitiman la homosexualidad y, de otra, la negación de recursos y beneficios a gays y lesbianas (Fraser, 2002: 58).

La otra corriente (teoría culturalista), toma en cuenta la problemática de la distribución desigual, pero asumiéndola como plena subsidiaria de la injusticia valorativa-cultural, es decir, que la injusticia de corte económico es un efecto secundario de la falta de reconocimiento:

De este modo, los defensores culturalistas de la política de la identidad sencillamente invierten las reivindicaciones de una forma primitiva de economicismo marxista vulgar; permiten que la política del reconocimiento desplace a la política de la distribución, justamente del mismo modo que en el pasado, el marxismo vulgar permitió que la política de la distribución desplazara a la política del reconocimiento (Fraser, 2002: 59).

El segundo problema planteado por Fraser es el problema de la reificación, relacionado con la esencialización y cosificación extrema de ciertas identidades de grupo, lo cual tiende a promover el separatismo, la intolerancia, el autoritarismo y la exclusión-discriminación intragrupal:

Paradójicamente, el modelo de la identidad tiende a negar sus propias premisas hegelianas. Aunque comienza asumiendo que la identidad es dialógica y construida por medio de la interacción con los otros sujetos, acaba valorando el monologuismo y dando por supuesto que las gentes que son inadecuadamente reconocidas pueden y deben construir su identidad por sí solas (Fraser, 2002: 60). 
Expuestos los dos problemas centrales de la política del reconocimiento centrada en el modelo de la identidad diferenciada, la autora se propone plantear una nueva forma alternativa de política de reconocimiento que permita superar o al menos mitigar tales problemas. Este nuevo planteamiento puede sintetizarse bajo la idea de falta de reconocimiento como subordinación de estatus. Con esta idea, Fraser, integrando sus anteriores aportes con el concepto de subordinación de estatus de estirpe weberiana, plantea una forma diferente y más compleja de abordar el problema de la política de la diferencia:

Desde esta perspectiva, lo que precisa de reconocimiento no es la identidad específica de un grupo, sino el estatus de los miembros individuales de un grupo como plenos participantes en la interacción social. La falta de reconocimiento, por lo tanto, no significa desprecio y deformación de la identidad de un grupo, sino subordinación social, en tanto que imposibilidad de participar como igual en la vida social [...] Por otro lado, de acuerdo con el modelo del estatus, la falta de reconocimiento no se transmite por medio de representaciones o discursos culturales que circulan libremente. Es perpetuada mediante modelos institucionalizados; en otras palabras, por medio del funcionamiento de instituciones sociales que regulan la interacción de acuerdo con normas culturales que impiden la igualdad. (Fraser, 2002: 61)

En otras palabras, Nancy Fraser resalta el hecho de que en términos del reconocimiento se trata de aspirar no a la valorización (reificación) de la identidad, en este caso del sector LGTBIQ, sino, por el contrario, de superar una subordinación de estatus estructural, es decir, que los integrantes del sector "logren participar plenamente en la vida social y puedan interactuar con otros en pie de igualdad". Así, "estas reivindicaciones pretenden desinstitucionalizar los modelos de valor cultural que impiden una participación igualitaria y reemplazarlos por modelos que la favorezcan". Asimismo, Fraser señala que tal falta de reconocimiento no se transmite por medio de los discursos o representaciones culturales que circulan en la sociedad, sino mediante modelos institucionalizados que regulan la interacción con normas culturales que impiden la igualdad real. Un ejemplo de esto es el debate sobre la unión de parejas del mismo sexo:

Consideremos nuevamente el caso de las leyes matrimoniales que impiden la participación igualitaria de gays y lesbianas. Tal y como lo he explicado anteriormente, el origen de esta injusticia es la institucionalización legal de un modelo cultural heterosexista que construye a los heterosexuales como normales y a los homosexuales como perversos. Remediar esta injusticia 
pasa por desinstitucionalizar dicho modelo de valor y reemplazarlo por uno alternativo que promueva la igualdad (Fraser, 2002: 63).

Es fundamental en este punto recalcar de nuevo la forma como la autora matiza o modula su posición con respecto a la salida socialista-deconstructiva expuesta en su artículo “¿De la redistribución al reconocimiento?” (en Fraser 1997) y a partir del modelo del estatus plantea una nueva salida menos radical o apocalíptica al problema del no reconocimiento de las identidades colectivas. De igual forma, su modelo basado en el estatus no cierra la puerta a ninguna de las salidas al problema expuestas más arriba ni privilegia jerárquicamente ninguna, es decir, admite el tipo de reconocimiento liberal (universalista), el deconstructivo y el reconocimiento que afirma la diferencia, utilizando en algunos casos un tipo de esencialismo estratégico. En otras palabras la superación de la subordinación de estatus de las identidades colectivas negativamente discriminadas se daría a partir de una lucha múltiple en diferentes frentes (sistema legal, sistema económico, sistema socio-cultural, sistema educativo, medios de comunicación etc.) que tendrían como fin la transformación de las instituciones sociales fundadas en la cultura que regulan la interacción e "instaurando nuevos modelos de valor que promuevan la participación igualitaria en la vida social":

Entendiendo el reconocimiento como una cuestión de estatus, y examinando su relación con la clase económica, se pueden dar pasos, si no para solucionar totalmente el desplazamiento de las luchas por la distribución, sí para mitigarlo; y evitando el modelo de la identidad, se puede comenzar a reducir, si no a disipar totalmente, la peligrosa tendencia a reificar las identidades colectivas (Fraser, 2002: 68).

Como he venido argumentando hasta aquí, considero que la propuesta intermedia de Nancy Fraser tiene un gran valor filosófico y político al intentar plantear una respuesta integradora al debate por el reconocimiento del sector LGTBIQ. La propuesta es integradora en dos sentidos distintos: primero, integra las luchas por el reconocimiento y las luchas por la redistribución; segundo, integra las salidas políticas de corte procedimental con las salidas políticas de corte transformativo. Pasaré ahora a subrayar las virtudes que encuentro en tal propuesta para terminar relacionándola con la construcción del proyecto democrático radical anti-totalitario.

Considero, en primer lugar, que el éxito de la propuesta de Fraser para entender el problema del reconocimiento político, jurídico y social del sector LGTBIQ como una cuestión de estatus radica en su realista y pragmática apuesta por conciliar políticamente las salidas de corte procedimental/progresivo, que hacen énfasis en la petición de derechos humanos fundamentales, y las salidas de corte radical/ 
transformativo, que abogan por una transformación revolucionaria de la estructura cultural valorativa que desestabilizaría progresivamente todas las identidades colectivas existentes. $\mathrm{O}$, en otras palabras, concilia la valiosa crítica deconstructivista a nuestra cultura (androcéntrica, patriarcal, heterocéntrica) con una salida normativa moderada centrada en la exigencia de derechos humanos fundamentales. En ese orden de ideas creo que la idea central de la propuesta de Fraser con respecto al sector LGTBIQ sería la siguiente: sabemos y estamos de acuerdo con la crítica a los mecanismos históricos y hegemónicos institucionalizados que han producido la subordinación de este amplio sector humano, pero reconocemos que la superación de tal subordinación requiere múltiples acciones en múltiples niveles del terreno político, que incluyen en ciertos casos la necesidad de exigir derechos humanos fundamentales, bajo una base que incluya la igualdad de estatus de las personas que tengan una orientación sexual no hétero y una expresión o identidad de género no tradicional. Así se puede entender que la desigualdad política, económica, jurídica, social, del sector LGTBIQ sea un problema de subordinación que conlleva a su dominación y que la lucha por la igualdad plena de estatus es la batalla contra todas las diversas formas de subordinación en el campo simbólico, en el campo jurídico y en el campo económico. En palabras de Fraser:

La superación de la homofobia y el heterosexismo requiere cambiar el orden de estatus sexual, desinstitucionalizar los patrones heteronormativos de valor y reemplazarlos por unos patrones que expresen la igualdad de respeto hacia gays y lesbianas (...) En principio, esto podría hacerse de formas diferentes: por ejemplo, reconociendo la especificidad homosexual o reconstruyendo la oposición binaria hetero-homo. En el primer caso la lógica del remedio consiste en valorizar el carácter del grupo mismo reconociendo su particularidad. En cambio, en el segundo, consiste en eliminar al grupo como tal (Fraser-Honneth, 2006: 28).

Además, Fraser subraya con su propuesta que lo que precisa de reconocimiento no es la identidad colectiva particular del sector LGTBIQ, sino el estatus de los miembros individuales de tal sector como plenos participantes en la interacción social. Como vimos, tales miembros del sector LGTBIQ sólo se agrupan o articulan a partir de la exclusión en lo que se denomina un "esencialismo estratégico", opuesto a un esencialismo reificado. Es decir, su déficit de reconocimiento no está relacionado con el irrespeto o deformación de su singular identidad colectiva sino con mecanismos institucionalizados de subordinación social que les han imposibilitado participar como iguales en la vida social. Es decir, el gran problema de la identidad tan denunciado por los teóricos deconstruccionistas queda entonces reducido a un asunto particular, individual, no colectivo, que impedirá la reificación de cierto tipo de identidad 
que ha sido siempre generador de nuevas exclusiones y discriminaciones. De esta forma, para el sector LGTBIQ podrá iniciarse realmente el proyecto de la construcción de la democracia radical.

\section{La propuesta de pluralismo agonístico de Chantal Mouffe para la construcción de la democracia radical}

La propuesta de democracia radical de Mouffe se fundamenta en cuatro puntos. Primero, carácter constitutivo de la división social y del antagonismo humano insoslayable: la reivindicación del papel del poder, su inerradicabilidad y del conflicto humano como esenciales rasgos de la política. Explícitamente Mouffe se sitúa en la tradición de Maquiavelo, reforzada por la propuesta de Carl Schmidt de comprender "lo político" ligado al antagonismo y hostilidad propia de las relaciones humanas y "la política" ligada al establecimiento de un orden, de una forma de organización que siempre será conflictiva por estar atravesada por "lo político". Bajo este enfoque plantea la necesidad de crear instituciones democráticas que permitan transformar el antagonismo (relación con el enemigo) en agonismo (relación con el adversario). Aquí se puede relacionar esta idea de "agonismo" con la propuesta de Fraser de superar la subordinación de estatus, para que las instituciones democráticas consideren a la persona LGTBIQ como un par, como un igual, como un interlocutor válido: en últimas como un adversario en el terreno político.

Segundo, crítica al proyecto totalizante de la democracia liberal: una crítica a los principios de universalidad, 6 racionalidad e individualidad de la democracia liberal y a su desconocimiento del papel esencial desempeñado por el antagonismo, las relaciones de fuerza, la hegemonía y el poder. Tal crítica sienta sus bases en presupuestos posmodernos como la disolución del sujeto unitario, la crítica de la noción de identidad y el antiesencialismo retomados por la autora de su lectura de Foucault, Derrida, Lacan, de Wittgenstein y de Gadamer. En otras palabras la posmodernidad en filosofía política debe ser entendida como:

Un reconocimiento de la imposibilidad de cualquier fundación última o legitimación final constitutiva del advenimiento de la forma democrática de la sociedad, y por ende, de la modernidad misma (Mouffe, 1999:30).

\footnotetext{
${ }^{6}$ La autora nos presenta una muy interesante crítica al fracaso en la actualidad de las ideas racionales liberales rawlsianas de "identidad posconvencional", del "consenso traslapado", de la "posición original bajo el velo de ignorancia", y de las ideas habermarsianas de "patriotismo constitucional" y "situación ideal de comunicación". Para tal fin la autora contrasta los orígenes kantianos de tales ideas basados en la regla de universalización como principio supremo con la noción aristotélica de prbonesis y ethos, que reconocen los rasgos culturales e históricos de una comunidad como fin último de los juicios, en los cuales siempre predominará lo razonable por encima de lo demostrable.
} 
Tercero, crítica al proyecto comunitarista y reivindicación de la multiplicidad de las posiciones de sujeto: a partir de esta imposibilidad de fundamentos últimos, de la imposibilidad de constituir la sociedad como un conjunto cerrado, homogéneo, autosuficiente, toma fuerza la reivindicación de la multiplicidad de las posiciones de sujeto que permitan captar la diversidad y complejidad de las relaciones sociales y la multiplicidad e interconexión de relaciones de subordinación que pueden afectar a un individuo:

Para poder pensar hoy la política y comprender la naturaleza de las nuevas luchas y la diversidad de las relaciones sociales que la revolución democrática ya ha desplegado, es indispensable desarrollar una teoría del sujeto como agente descentrado, destotalizado, de un sujeto construido en el punto de intersección de una multiplicidad de posiciones subjetivas entre las que no hay ninguna relación a priori o necesaria y cuya articulación es consecuencia de prácticas hegemónicas (Mouffe, 1999: 31).

Cuarto, hacia una hegemonía de valores democráticos: la reivindicación del antagonismo y del conflicto, la crítica al racionalismo, al universalismo que siempre es un esencialismo y la multiplicación de las posiciones subjetivas puede llevar a la creación de una nueva hegemonía de valores democráticos que profundice la actual democracia. Así el proyecto democrático radical y plural implica luchar por el establecimiento de una nueva hegemonía. Una filosofía política democrática radical tiene el objetivo de profundizar la revolución democrática, radicalizando los valores de libertad y de igualdad y dando un sentido común a las distintas luchas sociales contra la dominación, es decir, "como articulación de las luchas contra las diferentes formas de subordinación de clase, de sexo, de raza etc.; así como de aquellas otras a las que se oponen los movimientos ecológicos, antinucleares y antiinstitucionales". Sólo así podrá empezar a ser realidad el concepto de pluralismo agonístico para el cual:

La finalidad de la democracia radical no es ni negociar un acuerdo entre intereses ni crear un consenso racional, sino crear las condiciones de posibilidad para la expresión de una confrontación «agonística» entre puntos de vista en conflicto. Este modelo agonístico puede resultar por lo tanto más receptivo a la multiplicidad de voces que una democracia pluralista comprende y a la complejidad de la estructura de poder que este sistema de diferencias implica. Mediante el reconocimiento de la naturaleza real de sus fronteras y de las formas de exclusión que éstas representan, en lugar de pretender presentarlas como una necesidad para el "libre ejercicio de la razón pública", este pluralismo agonístico evita toda tentativa de clausura del espacio democrático mediante apelaciones a la racionalidad o a la moral. En lugar de intentar eliminar las pasiones o de relegarlas a la esfera privada con el fin de alcanzar un consenso supuestamente racional en la esfera pública, afirma que las políticas democráticas deberían 
tener como finalidad movilizar estas pasiones hacia designios democráticos (Mouffe, 1999: 117).

Este llamado de Mouffe a la radicalización de la democracia está también relacionado con la radicalización del concepto clásico de libertad negativa potenciado con la crítica deconstructivista moderna a los presupuestos universalistas liberales. Esto implica fortalecer jurídicamente las libertades de corte negativo (libertad de) sobre una base no excluyente, es decir, que no privilegie una particular noción del bien o lo bueno, libertades políticas que se interpretan como ausencia de valoración, como espacio vacío que permite al individuo poder vivir su vida como lo desea sin atentar contra los derechos de los demás. Es en este sentido donde se pueden entender los ideales de toda democracia que se considere radical y que cobran sentido en las exigencias del sector LGTBIQ: el ideal de la autenticidad o de ser auténtico (de auto-óntico: ser uno mismo) y el ideal de comodidad, es decir, sentirse cómodo consigo mismo, con su forma de vida, con lo que se es. Pero, de igual modo, es menester, revitalizar el concepto de libertad positiva (libertad para) y su relación con la participación política, en este caso, de nuestro poco participativo sector LGTBIQ:

Con el fin de asegurar las condiciones necesarias para evitar la coerción y la servidumbre, es indispensable que los individuos cumplan ciertas funciones públicas y cultiven unas determinadas virtudes cívicas. Para Maquiavelo, si uno ejerce la virtud cívica y sirve al bien común, lo hace con el fin de garantizarse un cierto grado de libertad personal que le permita perseguir sus fines propios. Nos encontramos aquí con una concepción muy moderna de la libertad individual articulada a una vieja concepción de libertad política, fundamental para el desarrollo de una filosofía política radical (Mouffe, 1999: 41).

En otras palabras, el ejercicio de la ciudadanía democrática radical no es una identidad entre otras identidades como en el liberalismo, ni la identidad dominante que es impuesta a otras. Tal ejercicio es un principio de articulación que afecta a las diferentes posiciones subjetivas del agente social. La construcción de una ciudadanía democrática radical es la construcción de un "nosotros” preciso para actuar en política y transformar la realidad, permitiendo la identificación de los múltiples actores que luchan por la abolición de todas las formas de dominación y subordinación.

\section{Bibliografía}

- Arango, Carlos, 2006, "Psicología política y cultura patriarcal", Ponencia presentada en el Simposio internacional de Psicología Política, Barcelona. 
- Bourdieu, Pierre, 1988, La distinción: criterios y bases sociales del buen gusto social, Madrid: Ed. Taurus. ,2000, La dominación simbólica, Barcelona: Ed. Anagrama.

Butler, Judith, 1993, Cuerpos que importan. Sobre los limites materiales y discursivos del "sexo", Buenos Aires: Ediciones Paidós. ,1990, El género en disputa, México, Ed. Paidós (2001).

Butler, Judith, Ernesto Laclau y Slavov Zizek, 2003, Contingencia, hegemonía y universalidad, Buenos Aires: Ediciones FCE.

- Castellanos, Gabriela, 2004, Textos y prácticas de género, Cali: Ed. UV.

- Fraser, Nancy, 2002, "Nuevas reflexiones sobre el reconocimiento", en: New Left Review, No.4.

1997, Institia Interrupta: Reflexiones críticas desde la posición postsocialista, Bogotá: Siglo del Hombre Editores.

- Fraser, Nancy y Axel Honneth, 2006, Redistribución o reconocimiento, Madrid: Ediciones Morata.

- Kymlicka, Will, 2000, Ciudadanía Multicultural, Barcelona: Ed. Paidós.

- Mérida, Rafael, 2002, Sexualidades transgresoras, Barcelona: Icaria Editores.

- Mouffe, Chantal, 1999, El retorno de lo politico. Comunidad, ciudadanía, pluralismo y democracia radical, Barcelona: Ediciones Paidós.

- Mouffe, Chantal y Ernesto Laclau, 1989, Hegemonía y estrategia socialista. Hacía una radicalización de la democracia, Madrid: Ediciones Siglo XXI.

- Preciado, Beatriz, 2001, Manifiesto Contra-sexual, Madrid: Ed.Opera Prima.

- Rawls, John, 1995, Liberalismo politico, México: Fondo de Cultura Económica.

- Sabsay, Leticia, 2006, "Política de lo transformativo: lenguaje, teoría queer y subjetividad", en: www.iigg.fsoc.uba.ar/.../3JornadasJovenes/Templates/Eje\%20 identidad-alteridad/Sabsay/identidad.pdf

- Taylor, Charles, 1995, "La política del reconocimiento", en: Taylor, Charles, Argumentos Filosóficos, Ediciones Paidós. Barcelona.

- Velandia, Manuel, 2006 "De la movilidad en la identidad sexual, en la identidad política y en la identidad sexual política", Conferencia dictada en Cali a los líderes y lideresas del sector LGBT.

- Young, Iris M., 1990, La justicia y la política de la diferencia, Madrid: Cátedra. 
